\title{
INVESTIGACIONES GEOGRAFICAS
}

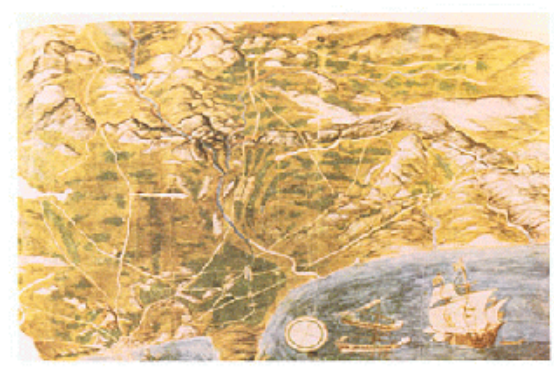

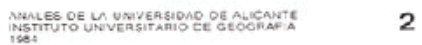

[7]

\section{LA PROPIEDAD DE LA TIERRA EN LA LAGUNA DE VILLENA}

\author{
Antonio Gil Olcina
}

\footnotetext{
*Este trabajo ha sido realizado dentro de los planes de investigación de la Comisión Asesora de Investigación Científica y Técnica.
}

A occidente del gran afloramiento triásico que divide la llanada cuaternaria de Villena se encontraba una amplia cuenca artesiana, ocupada por extensos sectores lacustres, que se prolongaba por los términos de Caudete y Sax. Hacia el interior de esta cuenca cerrada vierten los caudales subterráneos de una serie de estructuras mesozoicas con áreas de alimentación considerables. Los mantos acuíferos, retenidos por el Keuper, y las formaciones arcillosabulosas del Cuaternario, revisten excepcional importancia.

El aguazal más extenso, la llamada Laguna de Villena, se hallaba limitada por los cabezos de Muñoz, Salero y Fraile. En 1803 se iniciaron, bajo la supervisión de Juan de Villanueva y la dirección efectiva de Antonio de Abajo, los trabajos de desecación, que rescataron para el cultivo casi 1.500 hectáreas. La obra de más envergadura fue la excavación de la Acequia del Rey, emisario artificial que enlaza con el Vinalopó. En nuestro siglo la explotación intensiva de pozos ha hecho desaparecer el aprovechamiento de aguas caballeras y ocasionado un fuerte descenso del manto freático, con serio riesgo de salinización de los acuíferos ${ }^{1}$.

\section{BONIFICACIÓN DE LA LAGUNA}

El saneamiento de la Laguna constituía una vieja aspiración de las dos mayores poblaciones del valle del Vinalopó, Villena y Elche, por motivos diferentes. Las ventajas

1 MIRA CÁNOVAS, F.: «Importancia y significación de las aguas subterráneas para Villena», Día de la Provincia, 1976, I.D.E.A., págs. 71-82. 
esperadas por Villena consistían en la erradicación de [8] la endemia de tercianas, debida al estancamiento de las aguas, y en el rescate de nuevas tierras para el cultivo; en cambio, Elche perseguía, con particular ahínco, el incremento de sus disponibilidades hídricas. Contrarias a la desecación eran Sax, Elche y Novelda, que temían distintos perjuicios.

Los pleitos sobre el disfrute de los sobrantes de Villena y, en especial, por el aprovechamiento de la Fuente del Chopo enfrentaron secularmente a los citados pueblos; si bien, como observa García Martínez ${ }^{2}$, Sax y Elda llevaron la mejor parte por razones de proximidad, con daño de Elche. Villena, sin dificultades para atender el riego de su Huerta, se limitaba a ingresar, en concepto de canon, diversas cantidades en la tesorería de Propios.

Una iniciativa conjunta de Villena y Elche en 1760 para desaguar la Laguna tropezó con la enconada oposición de Sax, Elda y Novelda. La reunión de los comisionados de todos estos pueblos en Sax, el año 1761, no consiguió conciliar posiciones y fracasó igualmente un intento de mediación del famoso obispo de Orihuela Tormo. Sin embargo, unos años después, el momento histórico, coincidente con el apogeo del reformismo borbónico, favoreció las pretensiones de Villena y Elche, que no cejaron en su empeño y lograron finalmente interesar a la Corona.

Merece la pena recordar que Villena era entonces parte de la Provincia de Murcia, uno de los territorios más beneficiados por la política de colonización interior que impulsaba directamente el propio Floridablanca. No es mera coincidencia que el mismo año de 1785 en que se eleva al monarca a través de la Secretaría de Hacienda un detallado informe sobre el desagüe de la Laguna de Villena, el arquitecto Jerónimo Martínez de Lara dirigiese también a Carlos III un memorial en el que exponía la posibilidad de regar 47.000 fanegas (13.137 ha) del Campo de Lorca mediante la construcción de dos grandes presas en las gargantas de Puentes y Valdeinfierno; se iniciaba con ello una de las más ambiciosas empresas de colonización interior acometidas por el reformismo carlotercista ${ }^{3}$.

En franco contraste con la inusitada celeridad que presidió la construcción de los embalses lorquinos, el comienzo de las obras de la Laguna se demoró casi cuatro lustros; para entonces se habían producido una serie de hechos del máximo interés, tales como el estallido de la Revolución Francesa, el alejamiento de Floridablanca, el encumbramiento de Godoy y en el ámbito murciano la ruina de la presa de Puentes y el aterramiento de Valdeinfierno. Cuando en 1806 Carlos IV nombró Protector de las Reales Obras de Lorca y [9] Águilas al perseguido Floridablanca la hermosa aventura reformista en el Campo de Lorca había tocado a su fin. Poco antes, ya en las postrimerías del período reformista, se iniciaba el saneamiento de la Laguna de Villena, en virtud de la Real Orden de 23 de abril de 1803 por la que Carlos IV comisionaba «a Don Juan de Villanueva, su Arquitecto Mayor, para disponer y executar el desagüe de la Laguna en los términos que se habían propuesto o aquellos que estimase el propio Villanueva» ${ }^{4}$.

El aplazamiento de la decisión definitiva casi veinte años, a pesar de la insistencia de Elche y Villena, encuentra explicación en el contenido de una Real Orden de septiembre de 1785 por la cual se disponía que Juan de Villanueva pasara a reconocer la Laguna y Aguas de la Ciudad de Villena, con el encargo de valorar «el perjuicio que causan a dicha Ciudad y el que

${ }^{2}$ GARCÍA MARTÍNEZ, S.: «Evolución agraria de Villena hasta fines del siglo XIX», Cuadernos de Geografia, núm. 1, 1964, págs. 184-187.

${ }^{3}$ GIL OLCINA, A.: «Los embalses de Puentes y Valdeinfierno», Actas del III Congreso Nacional de Historia de la Medicina, Valencia, 1965, págs. 277-286.

${ }^{4}$ R.O. de 23 de abril de 1803. Volumen encuadernado en que se trasladan por R.O., informes y diligencias sobre el desagüe de la Laguna de Villena, de la cual se incluye un plano. Años 1785-1817. Traslado de 1826. A.H.N., Junta de Incorporaciones y Consejo de Hacienda, leg. 11.522. 
pueden hacer a los otros Pueblos que han acudido al Consejo, así como que examinásemos el uso de ellas concedido a la Villa de Elda y el de las sobrantes cedido a la de Elche o el desagüe de la misma Laguna, viésemos el modo de salvar estos perjuicios si se pudiese y el aprovechamiento que se deviera hacer así de las dichas aguas como del terreno que dejasen libre.... ${ }^{5}$.

Efectivamente, Sax, Elda y Novelda aducían, como se ha dicho, diversos daños. Los síndicos de Sax señalaban que los caudales procedentes del desagüe «destruirían las orillas de la rambla con pérdida de algunas tierras cultivadas y harían más intransitable el paso de la misma para la comunicación con el camino de Alicante». Elda hacía hincapié en «el perjuicio que podría resultar de la infestación de las aguas depositadas en su costoso pantano» y Novelda, «que sigue y cree ser la más perjudicada», a causa del «uso que hoy hace para beber puramente de las aguas de la Fuente del Chopo y filtrados de la Laguna ${ }^{6}$. Con todo, luego de apuntar soluciones a los problemas concretos planteados por cada pueblo, el informe concluía que "Queda demostrado que la Laguna puede desaguarse en el día cuasi totalmente, dejando correr las aguas por la acequia del Conde, y de ello se infiere que no puede ser de gran consecuencia la obra que corresponde hacer para ello».

El desagüe de la Laguna a través de la Acequia del Rey requirió una inversión total de 1.444.496 reales, entregados por la Tesorería de Rentas de [10] Murcia en cumplimiento de las reales órdenes de 23 de abril y 15 de junio de $1803^{7}$.

\section{APEO, JUSTIPRECIO E INTENTO FALLIDO DE DESAMORTIZACIÓN}

En septiembre de 1805 el Subdirector de las Reales Obras de Desagüe de la Laguna de Villena Don Antonio de Abajo ordenó que un agrimensor deslindase y dos peritos labradores verificasen las tierras panificadas e incultas acotadas en dicho aguazal.

Un mes después, la Real Orden de 19 de octubre de 1805 dispuso que el hasta entonces Corregidor de Requena Don José Reig y Ferre, designado ahora para idéntico cargo en Villena así como Juez Especial para entender en la bonificación de la Laguna, se trasladase, en compañía del Arquitecto Mayor Don Juan de Villanueva, a dicha ciudad con la finalidad de formar «el plan que estimen oportuno para la transacción y venta de los terrenos comprendidos en la laguna situada en el término de aquella ciudad, y ocupados por las aguas de ella, la que se halla ya desaguada, en los términos más ventajosos a la Real Hacienda...» ${ }^{8}$. La Demostración General elaborada, bajo la supervisión directa de Reig y del Subdirector Don Antonio de Abajo, por dos peritos de Villena y otros dos de Bocairente, ofrece el detalle siguiente de superficies y precios:

\section{LAGUNA Y SUS LADERAS}

${ }^{5}$ Volumen encuadernado en que se trasladan por R.O., op. cit., «Real Orden de 7 de septiembre de 1785, comunicada por el conde de Floridablanca a Juan de Villanueva, para el reconocimiento de la Laguna y aguas de la ciudad de Villena».

${ }^{6}$ Volumen encuadernado en que se trasladan por R.O., op. cit., «Exposición contradictoria de las villas de Sax, Elda y Novelda».

${ }^{7}$ Colección de discursos parlamentarios, defensas forenses y producciones literarias de Don Joaquín María López (Publicadas por su hijo Don Feliciano López). Madrid, Imp. de Manuel Munuera, 1857, págs. 119-120.

${ }^{8}$ Volumen encuadernado en que se trasladan por R.O..., op. cit., «Comisión de Don José Reig y Ferre para la venta de los terrenos de la Laguna de Villena». 


\section{Tahúllas \\ Reales}

1 tahúlla $=1852 \mathrm{~m}^{2}$

Desde el Puente del Salerno a la Fuentecilla, tierras incultas de levante

En la parte de Poniente, tahúllas pradales e incultas

De superior calidad en la Laguna desaguada a la Parte de Poniente

De la misma parte de poniente, Laguna desaguada de $2 .{ }^{\text {a }}$ calidad

En la misma parte de poniente, lagunilla desaguada

Laguna desaguada en la parte de levante que subdivide el azarbe principal, de mediana calidad

Laguna desaguada en la parte de levante subdividida por el azarbe principal, de regular calidad

La parte de la Lagunilla situada a levante dividida por el azarbe y de inferior calidad 
Primeramente, tierras no inundadas al tiempo

del desagüe a la parte de levante

Últimamente, tierras no inundadas a la parte

de poniente, incluso la llamada Real

Tahúllas comprendidas en esta demostración $=12.786^{1 / 2}$

Valor $=3.721 .747^{8}$ reales de vellón

«No se incluyen $1.823^{1 / 2}$ tahúllas, que se justipreciaron como panificadas y corrientes en la declaración de 2 de septiembre último en la cantidad de: 384.974 reales de vellón.

Beneficio por el desagüe $\underline{154.737^{17}}$

$$
539.711^{17}
$$

cuyo justiprecio debe repartirse en su debido tiempo y después véase si son del Rey o de particulares, en este caso hagan servicio correspondiente. [12]

Igual suerte deben seguir todos los Prados que se encuentran bajo la parada de los Moros, y a la parte superior de la Laguna, lo que se consultará en su oportuno tiempo. Villena y noviembre, nueve de mil ochocientos y cinco. Juan de Villanueva. José Reig y Ferre»?.

Efectuada la tasación, los comisionados plantearon la necesidad de verificar los títulos de propiedad y concluyeron que, en todo caso, los particulares beneficiados por el desagüe debían hacer un servicio pecuniario a la Corona mediante prorrata del coste de aquél o pago de una tercera parte del valor de la finca en el momento de su entrega.

Asimismo insinuaban la conveniencia de construir la red de riegos, organizar espacialmente las ventas y reconocer a los colindantes el derecho de adquisición preferente. Como posibles alternativas para las tierras de la Real Hacienda se sugerían la venta en pública subasta de parcelas no inferiores a 100 tahúllas o el reparto de suertes de veinte o más tahúllas «entre colonos laboriosos con medio para su cultivo del mismo Pueblo de Villena o de los vecinos del Reyno de Murcia y Valencia que sean arrendadores y no tengan propiedad, por el

\footnotetext{
9 Volumen encuadernado en que se trasladan por R.O., op. cit., «Demostración General de las tierras de la Laguna».
} 
tiempo y demás condiciones y canon que su Magestad tubiese a bien determinar» ${ }^{10}$.

La abierta hostilidad al saneamiento de la Laguna de los más prominentes miembros del patriciado de Villena, acentuada por la prohibición de que los ganados entrasen a pastar en las tierras bonificadas, alcanzó su ápice cuando el Corregidor Reig y el Subdirector don Antonio de Abajo propusieron que se declarasen propias de la Real Hacienda no sólo las 8.638 tahúllas propiamente desaguadas sino asimismo las 4.106 tahúllas de pastizales por considerarlas mostrencas, al tiempo que se exigían los títulos de propiedad y, en su caso, la compensación por mejoras a quienes aparecían como dueños de las 1.833,5 tahúllas cultivadas.

Esta decisión interfería, a todas luces, un largo proceso de privatización de tierras realengas a favor de la oligarquía nobiliaria que tradicionalmente había detentado el gobierno del concejo de Villena y cuyos linajes más destacados se hallaban unidos por estrechos vínculos de parentesco. La pugna fue feroz y concluyó con los asesinatos, en 1808, a manos de las turbas, del Corregidor Reig, del Subdirector Don Antonio de Abajo y del Escribano Nicolás Hernández, tildados hábil e injustificadamente de afrancesados. Concluía así un episodio más, esta vez cruento, del enfrentamiento entre reformistas y privilegiados, que más allá de la disputa ideológica incluía la lucha por el poder y un agudo conflicto de intereses. [13]

En este marco de enorme tensión local, el astronómico crecimiento de la Deuda Pública y las urgencias de la Real Hacienda decidieron la venta en pública subasta, haciéndose saber, a través de Real Orden de 11 de noviembre de 1806, «que por lo que resta de este año se admitirá a todo comprador las posturas que haga a el todo o parte de las 10.622 tahúllas y $3 / 4$ de tierra que ocupaba con sus aguas esta Real Laguna», así como «las que se encontraban pradales, incultas y alagadas en 23 de abril de $1803 \ldots$ sin omitir la venta de las comisadas y que se vayan comisando por no hacer sus titulados dueños el servicio a la Corona por los mejoramientos ${ }^{11}$.

Seis meses después del anuncio de subasta no se había producido ni una sola solicitud de compra. El Corregidor Reig justificó el fracaso de la operación por el mayor atractivo que ofrecían a los posibles adquirientes los bienes desamortizados en virtud de la Real Cédula de 21 de febrero de 1805 y, sobre todo, del Breve Pontificio de 12 de diciembre de 1806 por el cual Pío VII facultó a Carlos IV para enajenar «la séptima parte de los predios pertenecientes a las iglesias, monasterios, conventos, comunidades, fundaciones y a otras cualesquiera personas eclesiásticas, incluso los bienes patrimoniales de las cuatro Órdenes Militares y la de San Juan de Jerusalén».

Es obvio que no puede desconocerse la incidencia negativa de estas disposiciones desamortizadoras en el intento de venta por la Real Hacienda de sus posesiones de la Laguna de Villena; cabe preguntarse, en cambio, si lo fue hasta el extremo de impedir toda oferta. Podría pensarse que la causa del insólito retraimiento de compradores fue más compleja e incluía un saludable respeto a poderosas reacciones locales; los asesinatos, dos años más tarde, del Corregidor Reig y del Subdirector Don Antonio de Abajo parecen abonar esta hipótesis.

El Corregidor mostró la necesidad de aplazar la venta a tiempos más propicios y sugirió que ínterin se cediesen las tierras en contrato temporal con la percepción de dos diezmos, es decir, el diezmo que se atribuía la Corona por tratarse de novales y otro que en calidad de partición de frutos imponía como dueña de las tierras. Así se hizo y, suprimido el diezmo eclesiástico, la Corona y después los derechohabientes por compra mantuvieron esas percepciones hasta 1912, fecha de la redención por los colonos del dominio directo. Bajo este régimen de tenencia, se entregaron para cultivo unas 3.000 tahúllas a casi trescientos vecinos.

\footnotetext{
${ }^{10}$ Volumen encuadernado en que se trasladan por R.O., op. cit., «Propuesta del Corregidor de Villena y Juez especial Don José Reig y Ferre para la enajenación de los terrenos de la Laguna».

${ }^{11}$ Volumen encuadernado en que se trasladan por R.O., op. cit., «Real Orden de 11 de noviembre de 1806».
} 


\section{DONACIÓN AL MARQUÉS DE LA LEALTAD}

Las posesiones de la Real Hacienda en la Laguna de Villena fueron objeto de donación por Fernando VII, en virtud de Real Orden de 11 de julio de 1825, a Don Bernardo Elío Leizaur, creado por Real Decreto de 20 de noviembre de 1823 marqués de la Lealtad e hijo del famoso general absolutista ajusticiado en Valencia el día 4 de septiembre de $1822^{12}$.

Dicha donación fue confirmada por Real Cédula de 22 de junio de 1826 en los términos siguientes: «... a vos Don Bernardo Elío en atención a los méritos y esplendor debido a la inmortal memoria de Vuestro Padre el difunto Capitán General de mis Reales Ejércitos Don Francisco Javier Elío sacrificado, inhumanamente, al bárbaro furor de los revolucionarios por su adhesión inalterable a la sagrada causa de la Religión y de la legitimidad de mi Real Persona, y para que podáis mantener y conservar con el decoro, lustre y esplendor correspondiente el glorioso título de Marqués de la Lealtad con que os he agraciado como Rey y Señor natural que soy no reconociendo Superior en lo Temporal, os hago donación Real, perpetua, pura, perfecta e irrevocable a vos Don Bernardo Elío de Leizaur, vuestros herederos y sucesores de la finca cercana a las Minas de azufre de Hellín, cuya renta anual es de veinte a veinticuatro mil reales, y de la Laguna de Villena que también produce anualmente veinticinco mil reales, ambas pertenecientes por justos y legítimos Títulos a mi Real Hacienda, y de que se os dio posesión Real Corporal, velcuasi quieta y pacíficamente, a saber de la Hacienda de Hellín en diez y siete de Agosto, y de la Laguna en veinte y dos del mismo mes del año próximo pasado de mil ochocientos veinte y cinco con todos sus derechos, frutos, rentas, emolumentos, regalías y preeminencias que me corresponden sin excepción ni reserva alguna y demás que en sí comprendiesen, para que gocéis y disfrutéis como cosa vuestra propia las fincas de que va hecho mérito, a cuyo fin os transfiero el absoluto dominio y propiedad que se requiere.... ${ }^{13}$.

Destaquemos algunas peculiaridades de la fórmula de donación. En primer término, la concesión al marqués de la Lealtad de regalías, extremo que atestigua el carácter singular de la merced. Por otra parte, se previene la comisión por parte de los sucesores de Don Bernardo Elío de delitos de los que se seguía la pena de incautación, por la voluntad regia de que «éstos sean privados de la sucesión de esta gracia, veinte y cuatro horas antes de cometer tales delitos o cualesquiera de ellos, reputando al delincuente como si no fuese in rerum natura». [15]

Resaltemos, por último, la invocación a los Fiscales de los Reales Consejos para que si alguien contradijese o disputase a Don Bernardo Elío o a sus sucesores la quieta y pacífica posesión del dominio de la Laguna «salgan a la voz y defensa, y os defiendan hasta que quedéis en el goce de esta gracia...»; curiosa paradoja por cuanto en los años finales del reformismo borbónico había sido tarea preferente de los Fiscales de los Reales Consejos la apertura de expedientes de incorporación a la Corona de regalías y señoríos, mientras ahora se les ordenaba que sostuviesen al marqués de la Lealtad en la posesión de las fincas separadas de la Real Hacienda.

Derogado el Decreto de 27 de septiembre de 1820 por Real Cédula de 11 de marzo de 1824, la Laguna de Villena quedó vinculada a la Casa del marqués de la Lealtad para que «le sirviese de Cabeza de Título y Mayorazgo a él, sus hijos y demás sucesores»; suprimidos los mayorazgos definitivamente por Real Decreto de 30 de agosto de 1836, la finca de la Laguna

12 GARCÍA GONZÁlEZ, J.: Prisión, enjuiciamiento y muerte del General Elio (1820-1822). Valencia, Secretariado de Publicaciones de la Universidad, 1983, pág. 183.

${ }^{13}$ Volumen Encuadernado en que se trasladan por R.O., op. cit., «Real Cédula de 22 de junio de $1826 »$. 
perteneció todavía a Don Bernardo Elío hasta la fecha de su incorporación al Patrimonio del Estado, al declararse nula y sin efecto la merced de Fernando VII.

Es de destacar que la donación de las tierras incluidas en la Demarcación de la Laguna de Villena al marqués de la Lealtad trajo consigo un cambio del régimen de tenencia, puesto que el monarca las concedió en dominio pleno, desconociendo todo dominio útil, y para encabezamiento de mayorazgo, institución ésta incompatible con la enfiteusis y los arrendamientos por plazo superior a nueve años.

Joaquín M. ${ }^{a}$ López en una intervención, el año 1835, a la que luego aludiremos, ante el Estamento de Procuradores, declaraba que el marqués había privado «a los enfiteutas del carácter de tales, bajo cuyo sólo concepto habían podido invertir sus sudores y caudales en reducir a cultivo estable unas tierras que antes sólo eran páramos inútiles, obligándoles a la ley dura de un arrendamiento que llevaba sobre sí el sello de la ilegalidad, los ha reducido a una clase poco menos que de feudatarios, y entre tanto los infelices han tenido que sufrir en silencio, porque tribunales especiales llamados protectores del marquesado hacían absolutamente desesperada la lucha...». Dos años más tarde, el diputado Joaquín M. a López hacía notar en las Cortes que «Descubierta la superficie de la tierra, se dio a censo enfitéutico a ciertos colonos que descuajaron aquellos terrenos incultos, invirtiendo en ellos los trabajos y los sudores de muchos años. Se les dio el dominio útil, sin más gravamen que pagar a la Real Hacienda un diezmo además del que se pagaba a la Iglesia; pero ellos transferían la propiedad por vida, por muerte, la miraban, en una palabra, como una tabla en el naufragio de la pobreza, como un recurso en la adversidad. La donación del Rey no respetó ninguno de estos precedentes: dio en pleno dominio al hijo mayor de Elío lo que era sólo de tantos infelices agricultores, y escudado con aquel título de espoliación, a todos arrebató el [16] fruto de sus fatigas y el objeto de sus esperanzas, no sólo tomando como dueño único y exclusivo lo que otros habían creado, sino haciéndoles pagar su propio trabajo, en un arrendamiento correspondiente al valor que entonces tenían las fincas» ${ }^{14}$.

Con independencia del apasionamiento que deja traslucir el alegato del diputado villenense y sin olvidar que el régimen de tenencia vigente hasta la donación más parece terraje que contrato puramente enfitéutico, es evidente que el nuevo propietario disipó cualquier duda e impuso arrendamientos a metálico, una vez valuadas las distintas heredades.

\section{REVERSIÓN AL ESTADO Y DESAMORTIZACIÓN DE LAS TIERRAS DE LA LAGUNA}

Tras el fallecimiento de Fernando VII, la convocatoria de Cortes por el Estatuto Real dio ocasión a que se planteara en el Estamento de Procuradores la incorporación al Estado de los bienes de la Real Hacienda donados por el extinto monarca al marqués de la Lealtad.

En efecto, con motivo de la discusión sobre el arreglo de la deuda interior, iniciada el día 30 de abril de 1835, los señores Don Joaquín M. ${ }^{a}$ López y conde de las Navas presentaron una Adición al artículo 5. ${ }^{\circ}$ para que «el Estamento declarase pertenecientes al Estado, y aplicables a la amortización de la deuda sin interés, los bienes de que hizo donación el señor Don Fernando VII al hijo del General Elío para que le sirvieran de dotación al título que le concedió de marqués de la Lealtad, en razón de que estos bienes correspondían al Estado en aquella época» ${ }^{15}$.

En apoyo de esta proposición intervino como firmante el propio Joaquín M. ${ }^{a}$ López, quien pronunció un visceral discurso contra la permanencia de la donación regia, calificándola

\footnotetext{
${ }^{14}$ Colección de discursos parlamentarios..., op. cit., págs. 116-117 y 356-357.

${ }^{15}$ Colección de discursos parlamentarios..., op. cit., págs. 115 y ss.
} 
de ilegítima en su origen y de indecorosa por su motivación. Sostuvo el famoso tribuno villenense que los bienes donados no pertenecían ala Corona sino a la Real Hacienda y que, aun en el primer supuesto, la donación resultaría nula de pleno derecho por contravenir la ley $8 .^{\mathrm{a}}$, título 5. ${ }^{\circ}$, libro $3 .^{\circ}$ de la Novísima Recopilación, que consideraba asimismo el proponente que la ley 9. a de los citados título y libro había revocado y anulado las mercedes y donaciones hechas desde 1464 por Enrique IV, y señalaba cómo la ley 11. a declaraba que las mercedes hechas por la sola voluntad de los Reyes eran revocables. [17]

Estimaba, en suma, que la donación regia vulneraba los principios más elementales del derecho público, contrarios a las enajenaciones arbitrarias en perjuicio de los intereses nacionales. Se preguntaba Joaquín M. ${ }^{a}$ López: «Si pues tales propiedades eran de la nación y nada tenía que ver con ellas el peculio particular de S.M., ¿podía éste donarlas para remunerar servicios, ¡y qué servicios, señores!; el de haber tendido las cadenas de la esclavitud y de la opresión sobre la patria, a quien todavía se quiso obligar a que pagase a quien la había asesinado! ${ }^{16} \mathrm{Y}$ concluía que «... donó quien no pudo donar, porque no eran suyas las fincas que donaba, y porque aunque lo hubieran sido estaba prohibida su enajenación por las leyes de aquella época ${ }^{17}$.

Sin embargo, puesta a votación la proposición de Don Joaquín M. ${ }^{a}$ López y del conde las Navas, fue desechada por el Estamento de Procuradores en su sesión de 19 de mayo de 1835, al entender la mayoría de la Cámara que el asunto quedaba fuera de su competencia y debía, en todo caso, plantearse ante los tribunales.

Dos años más tarde y en un marco político más propicio, que condujo a la Constitución de 1837, un grupo de diputados encabezado por Joaquín M. ${ }^{a}$ López formularon una proposición encaminada a conseguir «que se declarase nulo el título de marqués de la Lealtad, concedido al primogénito del general Elío y que se considerasen como bienes del Estado los que fueron donados para sostener dicho título» ${ }^{18}$. La comisión encargada dictaminó que el gobierno resolviese en lo tocante al título nobiliario y que por las Cortes se podía acordar la nulidad de la donación de bienes, como así lo dispuso el cuerpo legislativo, tras una nueva intervención el 11 de mayo de 1837 de Joaquín M. ${ }^{\mathrm{a}}$ López.

Revocada la donación e incorporadas las tierras de la Laguna de Villena al patrimonio del Estado, cambió el régimen de tenencia sustituyéndose el arrendamiento a metálico por el contrato enfitéutico, con el canon de doble diezmo. Esta forma jurídica de explotación perduraría hasta 1912, fecha del rescate del dominio directo por los diezmeros de la Laguna.

La titularidad del dominio directo pasó por distintas manos. En 1845 la Junta Superior de Venta de Bienes Nacionales acordó enajenar el dominio directo de las tierras censidas y el pleno de algunos saladares y prados que perduraban en la Demarcación de la Laguna de Villena.

Dichos bienes fueron adquiridos pro indiviso por el marqués de Remisa y Don Segismundo Moret y Quintana ${ }^{19}$, vecinos de Madrid, que compraron [18] asimismo tierras procedentes de la desamortización eclesiástica en el convento de las Virtudes y la labor de la Casa de Zúñiga; ambos financieros aparecen, en 1859, a la cabeza de los mayores propietarios en el término de Villena.

Los bienes comprados en la Laguna de Villena por el marqués de Remisa y Don

\footnotetext{
${ }^{16}$ Colección de discursos parlamentarios..., op. cit., pág. 120.

${ }^{17}$ Colección de discursos parlamentarios..., op. cit., pág. 121.

${ }^{18}$ Colección de discursos parlamentarios..., op. cit., págs. 353 y ss.

${ }^{19}$ GIL OLCINA, A.: El Campo de Lorca. Valencia, Dpto. de Geografía e Instituto «Juan Sebastián Elcano», del C.S.I.C., 1971, pág. 207.
} 
Segismundo Moret y Quintana, que incluían el dominio directo de las tierras cultivadas y el pleno de algunos saladares y prados, pasaron en 1888 al bodeguero y exportador de vinos manchego Luis Penalva Muñoz, quien al socaire de la favorable coyuntura suscitada por la invasión filoxérica de los viñedos franceses había obtenido grandes beneficios asociado a las casas «Moullet et Jeune»y «René Barbier» ${ }^{20}$.

El dominio directo fue rescatado por los colonos de la Laguna de Villena en 1912, año en que los hermanos Luis y Casimiro Penalva y Estela, hijos de Luis Penalva Muñoz, otorgaron escrituras de redención a 499 enfiteutas, confesando haber obtenido de las ventas una suma total de 300.000 pesetas $^{21}$. Acabaron así por acceder al pleno dominio de la tierra los descendientes y derechohabientes de los colonos que habían empezado a descuajar y cultivar las tierras de la Laguna de Villena a comienzos del siglo pasado.

Desde mediados delXVIII y por espacio de más de ciento cincuenta años la problemática de la Laguna de Villena había reflejado fielmente algunos de los más importantes avatares políticos de esa época.

${ }^{20}$ PIQUERAS HABA, J.: La vid y el vino en el pais Valenciano, Valencia, Institución Alfonso el Magnánimo, 1981, pág. 184.

${ }^{21}$ PIQUERAS HABA, J.: op. cit., pág. 165. Debo el conocimiento directo de la escritura de redención de censos a la cortesía de D. ${ }^{\text {a }}$ Remedios Belando Carbonell. 